\title{
Visual Outcome Following Scleral Fixated Intraocular Lens Implantation
}

\author{
Chunu Shrestha, Sabina Shrestha and Aprajita Manoranjan
}

Nepal Eye Hospital, Tripureshwor, Kathmandu, Nepal.

\section{ABSTRACT}

Introduction: Scleral fixated intraocular lens (SFIOL) implantation to correct aphakia offers superior visual rehabilitation in comparison to aphakic spectacles or contact lens. This study was done to evaluate a simplified technique of scleral fixation of posterior chamber intra-ocular lens (IOL) in terms of visual outcome and complications.

Methods: This was a prospective study enrolling 23 eyes of 23 patients who underwent anterior vitrectomy followed by ab-externo sclera fixation of posterior chamber IOL using 10.0 polypropylene sutures from January 2016 to February 2017 in a tertiary level Eye Hospital in Kathmandu, Nepal. Scleral flap was made at 3 and 9'o clock meridian to cover the knots which prevent erosion of the knots through conjunctiva. Main outcome measures were post-operative best corrected visual acuity and post-operative complications.

Results: Best corrected visual acuity were $6 / 6-6 / 18$ in $86.9 \%(n=20), 6 / 24-6 / 60$ in $8.7 \%(n=2)$ and worse than $6 / 60$ in $4.3 \%(n=1)$ at six months follow up. The mean spherical equivalent before surgery was +10.60 diopter and -1.14 diopter post-surgery. The common indications for scleral fixated intraocular lens were trauma in $60.86 \%(\mathrm{n}=14)$, surgical aphakia in $21.73 \%(\mathrm{n}=5)$, spontaneous posterior dislocation of lens in $13.0 \%(n=3)$ and subluxated intraocular lens in $4.34 \%(n=1)$. The common complications were astigmatism in $91.30 \%(n=21)$, decentered IOL in $4.34 \%(n=1)$ and uveitis in $4.35 \%(n=1)$.

Conclusion: Ab-externo sclerated fixated intraocular lens is a safe and effective method for visual rehabilitation with low post-operative risk.

Keywords: aphakia; astigmatism; scleral fixated intraocular lens

Correspondence: Chunu Shrestha, Nepal Eye Hospital, Tripureshwor, Kathmandu, Nepal. Email: chunu20@hotmail.com

To cite this article: Shrestha C, Shrestha S, Manoranjan A. Visual Outcome Following Scleral Fixated Intraocular Lens Implantation. Medical Journal of Shree Birendra Hospital. 2017;17(2):63-68.

DOI: http://dx.doi.org/10.3126/mjsbh.v16i2.18478

Conflict of Interest: None declared

This work is licensed under creative common license: http://creativecommons.org/ licenses/by-nc-nd/4.0/ ( Medical Journal of Shree Birendra Hospital 


\section{INTRODUCTION}

Scleral fixated intraocular lens (SFIOL) implantation is a standard procedure both in posttraumatic and postoperative aphakia. The use of an anterior chamber intra ocular lens (ACIOL) has also been described, but the long-term complications associated with these lenses are common, especially in eyes with shallow anterior chambers. ${ }^{1}$ Malbran and co-authors first reported trans-scleral sulcus fixation with sutures of posterior chamber lenses in aphakic patients who had had previous intracapsular cataract extraction in 1986.2

The placement of intra ocular lens in the posterior chamber rather than anterior or iris fixated lenses reduces the risk of various complications like keratopathy, damage to anterior chamber angle structure, pupillary block glaucoma, hyphema, uveitis, iris chafing, dislocation and pseudophakodonesis. ${ }^{3}$

Two surgical techniques, namely Ab-interno (inside out) and Ab-externo (outside in) has been explained. Ab- interno technique involves the passage of needle from the inside of the eye to the outside through the sclera ${ }^{4,5}$ whereas the Ab-externo technique involves the passage of a needle from the outside of the eye to the inside through the sclera. In our study Ab-externo technique was used for IOL implantation. In the Ab-externo method the intra ocular lens lies exactly in the ciliary sulcus 6 and the surgeon's view is never obscured. All the manipulation occurs in the iris plane decreasing the risk of vitreous hemorrhage. ${ }^{7}$

\section{METHODS}

This is a prospective, interventional hospital based study conducted in a tertiary level Eye Hospital in
Kathmandu, Nepal 1 from January 2016 to February 2017.

Cases with total absence of capsular bag and history of eye trauma or complicated cataract surgery causing aphakia were included in the study and those who completed 6 months follow-up for scleral fixated intraocular lens. Those who did not complete six month's follow-up were excluded from the study.

Demographic data, ocular history, indication for surgery, preoperative and postoperative best corrected visual acuity (BCVA), intraocular pressure, detailed anterior and posterior segment finding using stereoscopic slit lamp biomicroscopy and indirect ophthalmoscopy were recorded after taking the informed consent. Patients were evaluated on the day 1, day 7,1 month, 3 months and 6 months postoperatively. Intraocular lens position was assessed by a slit lamp examination with a dilated pupil, non-visibility of the optic edge in a mid-dilated pupil of $4 \mathrm{~mm}$ was considered as a good centration. The main outcome measures were final post-operative visual acuity and complications. Data were analyzed using SPSS (version 21).

Surgical Procedure: All procedures were performed under local anesthesia by a single surgeon. After preparing the patient, peritomy was done at 3 o'clock to 9 o'clock position. A partialthickness limbal-based scleral flap measuring $3 \mathrm{~mm}$ long and $2 \mathrm{~mm}$ wide was fashioned at the same position. A $7 \mathrm{~mm}$ corneal incision was made superiorly at $12 \mathrm{o}$ ' position and anterior chamber (AC) was entered through $3.2 \mathrm{~mm}$ knife. After forming the $\mathrm{AC}$ with viscoelastic substance, a complete anterior vitrectomy was performed. After 
reformation of $\mathrm{AC}$, a straight needle carrying a double armed 10-0 polypropylene suture was placed through the 9 o'clock sclera bed parallel to the iris and $0.8 \mathrm{~mm}$ to $2 \mathrm{~mm}$ posterior to the posterior surgical limbus. The needle tip was passed through the sulcus and behind the iris until it was visualized behind the pupil. In a similar manner, a 30-gauge needle was inserted through the 3o'clock sclera bed. The barrel of the 30 - gauge needle was inserted into the eye and the syringe was withdrawn from the eye, making a suture with a straight needle.. A loop of this suture was withdrawn through the corneal sclera wound. The loop of suture was cut, and one end securely tied to the superior haptic and the other end was tied to the inferior haptic. The lens was inserted into the sulcus, and rotated into position while removing slack from the attached sutures. Scleral flaps were closed, and the conjunctiva re-approximated. All patients were followed up on first day, one week,

one month, three months and six months after the surgical procedure.

During each visit, IOP, BCVA was examined along with anterior segment and posterior segment examination using slit lamp. These findings were noted on a proforma and analyzed subsequently.

Postoperative medications included topical drops (ofloxacin and prednisolone) given six times daily and tapered slowly for 4 weeks.

\section{RESULTS}

Twenty three patients were included in the study, with mean age of 50.74 years. Minimum age of the patient included was 11 years while the maximum age was 74 years. Out of 23 patients, 14 (60.9\%) were males and 9 (39.1 \%) were females. Presenting uncorrected visual acuity was from

Table 1: Visual acuity before and after surgery. $\quad(n=23)$

\begin{tabular}{|l|c|c|c|c|c|c|c|c|}
\hline $\begin{array}{l}\text { Visual } \\
\text { acuity }\end{array}$ & \multicolumn{2}{|c|}{$\begin{array}{c}\text { Uncorrected } \\
\text { pre-operative }\end{array}$} & \multicolumn{2}{c|}{$\begin{array}{c}\text { Uncorrected } \\
\text { post-operative }\end{array}$} & \multicolumn{2}{c|}{$\begin{array}{c}\text { BCVA } \\
\text { pre-operative }\end{array}$} & \multicolumn{2}{c|}{$\begin{array}{c}\text { BCVA } \\
\text { post-operative }\end{array}$} \\
\hline & $\mathrm{N}$ & $\%$ & $\mathrm{~N}$ & $\%$ & $\mathrm{~N}$ & $\%$ & $\mathrm{~N}$ & $\%$ \\
\hline $\mathbf{6} / \mathbf{6 - 6 / 1 8}$ & - & - & 6 & 26.1 & 13 & 56.5 & 20 & 87 \\
\hline $\mathbf{6 / 2 4 - 6 / 6 0}$ & 2 & 8.7 & 16 & 69.6 & 9 & 39.1 & 2 & 8.7 \\
\hline $\mathbf{5} / \mathbf{6 0 - 3 / 6 0}$ & 2 & 8.7 & - & - & - & - & - & - \\
\hline$<3 / 60$ & 19 & 82.6 & 1 & 4.3 & 1 & 4.3 & 1 & 4.3 \\
\hline
\end{tabular}

Table 2: Indications for scleral fixated intra ocular lens.

\begin{tabular}{|l|c|c|}
\hline Indications & Frequency & Percentage \\
\hline Trauma & 14 & 60.86 \\
\hline Surgical aphakia & 5 & 21.73 \\
\hline Spontaneous posterior dislocation of lens & 3 & 13.0 \\
\hline subluxated intraocular lens & 1 & 4.34 \\
\hline Total & 23 & 100 \\
\hline
\end{tabular}


Table 3: Post operative complications

\begin{tabular}{|l|c|c|}
\hline Complications & Frequency & Percentage \\
\hline Astigmatism & 21 & 91.30 \\
\hline Decentered IOL & 1 & 4.34 \\
\hline Uveitis & 1 & 4.34 \\
\hline Total & 23 & 100 \\
\hline
\end{tabular}

perception of light to $6 / 60$. The post-operative uncorrected visual acuity was from $1 / 60$ to $6 / 12$, the visual acuity was greatly improved by more than four lines in the Snellen visual acuity chart. The youngest patient of age 11 years had a postoperative visual acuity of 1/60 from perception of light pre-operative. He had undergone lensectomy at the age of 2 months and had not undergone amblyopia treatment which was the reason for not significant improvement in vision.

The post-operative BCVA was $6 / 6-6 / 18$ in $87 \%$ $(n=20), 6 / 24-6 / 60$ in $8.7 \%(n=2)$ and worse than $6 / 60$ in $4.3 \%(n=1)$ at six months follow up. The mean spherical equivalent before surgery was + 10.60 diopter and -1.14 diopter post-surgery, this was significant by Wilcoxon signed rank test $(\mathrm{p}$ value $=0.000)$.

Intra operatively, the cases were uneventful. The common indications of scleral fixated IOL were trauma in $60.86 \%(n=14)$, surgical aphakia in 21.73 $\%(n=5)$, spontaneous posterior dislocation of lens in $13.0 \%(\mathrm{n}=3)$ and subluxated intraocular lens $4.34 \%(n=1)$.

The common complications were astigmatism in $91.30 \%(n=21)$, decentered IOL in $4.34 \%(n=1)$ and uveitis in $4.35 \%(\mathrm{n}=1)$. The minimum astigmatism was $-0.25 \mathrm{DC}$ and maximum was -4.00 DC with mean astigmatism of -1.41 DC in this study. 18 patients had with the rule astigmatism, two patients had oblique astigmatism and only one patient had against the rule astigmatism.

\section{DISCUSSION}

Optical rehabilitation of patients with monocular aphakia presents a therapeutic challenge. Unilateral aphakic glasses cannot be prescribed because of magnification and anisoconia. The viable options therefore include ACIOL, iris fixated intraocular lens and scleral fixated posterior chamber IOL. Among them scleral fixated IOL can provide minimum magnification of the image as compared to other methods. ${ }^{8}$

In our study, the post-operative best corrected visual acuity was $6 / 6-6 / 18$ in $86.9 \%, 6 / 24-6 / 60$ in $8.7 \%$ and worse than $6 / 60$ in $4.3 \%$ at six months follow up. This is comparable with Lee and Yuen's work ${ }^{9}$ who reported best corrected visual acuity of 6/12 or better in 19 (76\%) out of 25 cases. Ghanem and colleagues ${ }^{10,11}$ reported postoperative BCVA of $6 / 9$ or better in $10(71.43$ $\%)$ out of 14 eyes undergoing scleral fixation of IOL. Similarly, Ozdek and co-workers ${ }^{12}$ reported improvement of postoperative BCVA $6 / 12$ or better in 14 eyes $(93.3 \%)$ undergoing scleral fixation of IOL. The youngest patient of age 11 had a postoperative visual acuity of $1 / 60$. He had undergone lensectomy at the age of 2 months and had not undergone amblyopia treatment which was the reason for not significant improvement in vision.

The most common post-operative complication in our series was astigmatism in $91.30 \%$, decentered IOL in $4.34 \%$ and uveitis in $4.34 \%$. The cause of astigmatism was tight sutures and IOL decentration. Ghanem and colleagues ${ }^{10}$ also reported astigmatism as most frequently occurring complication in three eyes $(21.4 \%)$. Similarly, Sasahara and Kiryu ${ }^{13}$ reported astigmatism in 12 eyes (13\%). Due to iris manipulation while doing 
scleral fixation of IOL, we noticed anterior uveitis in one eye which is comparable with the results of Kwong et. al. and Kanigowska K.14, 15

Due to the unavailability of foldable scleral fixating IOL, we did not use them in this study. The outcome could be improved further by using foldable IOL instead of rigid polymethyl methacrylate IOL as the former can be inserted by giving small incision as compared to later one. This can ultimately reduce the postoperative astigmatism. ${ }^{16}$ The haptics should be inserted with precision and placed accurately into the ciliary sulcus.
Nottage and colleagues ${ }^{17}$ in a study of 69 patients after transscleral fixation observed glaucoma in $5.8 \%$, cystic macular oedema in $5.8 \%$, bullous keratopathy in $4.3 \%$, retinal detachment in $1.4 \%$, uveitis in $1.4 \%$, keratitis in $1.4 \%$ and choroidal haemorrhage in $1.4 \%$ after 14 months of the follow-up. In our study we did not observe any severe complications.

\section{CONCLUSIONS}

The scleral fixation intra ocular lens is a safe and effective procedure in the absence of zonular or capsular support in cases of aphakia whether traumatic or post-surgical.

\section{REFERENCES}

1. Sawada T, Kimura W, Kimura T, et al. Long-term follow-up of primary anterior chamber intraocular lens implantation. J Cataract Refract Surg. 1998; 24:1515-1520.

DOI: https://doi.org/10.1016/S0886-3350(98)80176-4

2. Malbran ES, Malbran E Jr, Negri I. Lens guide suture for transport and fixation in secondary IOL implantation after intracapsular extraction. Int Ophthalmol. 1986;9:151-160.

DOI: https://doi.org/10.1007/BF00159844.

3. Azar DT, Clamen L, Flakier P. Secondary intraocular lens implantation. In: Principles and practice of ophthalmology. 2nded. Philadelphia: W.B Saunders Company. 2000:1514-1536.

4. Lwis JS. Ab-externo sulcus fixation. Ophthalmic Surg. 1991;22:692-695.

5. Chakrabarti A, Gandhi RK, Chakrabarti M. Ab-externo 4-point scleral fixation of posterior chamber intraocular lenses. J Cataract Refract Surg. 1999;25:420-426.

DOI: https://doi.org/10.1016/S0886-3350(99)80093-5

6. Mittelviefhaus H, Wiek J. Are fined technique of trans sclera suture fixation of posterior chamber lenses developed for cases of complicated cataract surgery with vitreous loss. Ophthalmic Surg. 1993;24:698-701.

7. Bleckmann H, Kaczmarek U. Functional results of posterior chamber lens implantation with sclera fixation. J Cataract Refract Surg. 1994;20:321-326.

DOI: https://doi.org/10.1016/S0886-3350(13)80585-8 
8. Kokame GT, Yamamoto I, Mandel H. Scleral fixation of dislocated posterior chamber intraocular lenses: Temporary haptic externalization through a clear corneal incision. J Cataract Refract Surg. 2004 May. 30(5):1049-56.

DOI: https://doi.org/10.1016/j.jcrs.2003.09.065

9. Lee VY, Yuen HK, Kwok AK. Comparison of outcomes of primary and secondary implantation of sclera fixated posterior chamber intraocular lens. Br J Ophthalmol. 2003;87:1459-1462.

DOI: https://doi.org/10.1136/bjo.87.12.1459

10. Ghanem VC, Ghanem EA, Ghanem RC. Monoscleral fixation IOL after extra capsular extraction of subluxated lenses in patients with Marfan syndrome. Arq Bras Oftalmol. 2004;64:763-767.

DOI: https://doi.org/10.1590/S0004-27492004000500013

11. Ganesh A, Al-Zuhaibi S, Sabt BI. Visual rehabilitation by scleral fixation of posterior chamber intraocular lenses in Omani children with aphakia. Ophthalmic Surg Lasers Imaging. 2009;40(4): 354-360.

DOI: https://doi.org/10.3928/15428877-20096030-01

12. OzdekS, Sari A, Bilgihan K, Akata F. Surgical treatment of hereditary lens subluxations. Ophthalmic Surg Lasers. 2002;33:309-313.

13. Sasahara M, Kiryu J, Yoshimura N. Endoscope-assisted trans scleral suture fixation to reduce the incidence of intraocular lens dislocation. J Cataract Refract Surg. 2005;31:1777-1780.

DOI: https://doi.org/10.1016/j.jcrs.2005.02.029

14. Kanigowska K, Grałek M, Karczmarewicz B. Trans sclerally fixated intraocular artificial lenses in children-analysis of long-term postoperative complications. Klin Oczna. 2007;109:283-286.

15. Kumar DA, Agarwal A, Jacob S. Sutureless scleral-fixated posterior chamber intraocular lens. J Cataract Refract Sur. 2011;37(11):2089-2090.

DOI: https://doi.org/10.1016/j.jcrs.2011.09.008

16. McAllister AS, Hirst LW. Visual outcomes and complications of scleral fixated posterior chamber intraocular lenses. J Cataract Refract Surg. 2011;37(7):1263-1269.

DOI: https://doi.org/10.1016/j.jcrs.2011.02.023

17. Nottage JM, Bhasin V, Nirankari VS. Long-term safety and visual outcomes of transscleral sutured posterior chamber IOLs and penetrating keratoplasty combined with transscleral sutured posterior chamber IOLs. Trans Am Ophthalmol Soc. 2009;107:242-50. 